\title{
A Study on Chinese EFL Learners' Phonetic Obstacles to Listening Comprehension*
}

\author{
Fanghui $\mathrm{Hu}$ \\ School of Foreign Languages, Jining Medical University, Rizhao, Shangdong Province, China
}

\begin{abstract}
Perceiving and identifying speech sounds are greatly important in listening comprehension. This paper aims to analyze Chinese EFL learners' Phonetic Obstacles to listening comprehension in terms of individual segments, sound change in fluent speech, stress, rhythm, intonation and English varieties. Based on the analysis, suggestions are proposed about how to overcome phonetic obstacles to improve Chinese EFL learners' ability of listening, including increasing phonetic teaching in listening, memorizing the sound form of words and designing tasks of dictation.
\end{abstract}

Index Terms - phonetic obstacles, listening comprehension, Chinese EFL learners

\section{INTRODUCTION}

In China, college English teaching has played an increasing emphasis on cultivating English application ability, especially English listening and speaking ability since reform of college English teaching in 2004. Most colleges and universities offer non-English majors a listening course in order to improve their listening ability. However, listening is still regarded as the weakest link in learning English.

Listening proficiency is influenced by many factors, such as knowledge about the topic, size of the listeners' vocabulary, mastery of the grammar, knowledge about the discourse, lack of listening strategies, excessive anxiety in listening and so on. Amongst these variables, the phonetic factor is too important to be neglected. In the process of teaching English listening, the author finds it common that some students, especially the low-achieving Chinese EFL learners, have great difficulties in identifying pronunciation of some phonemes or cutting stream of speech into cognizable words. The paper aims to analyze Chinese EFL learners' phonetic obstacles to listening comprehension and put forward some suggestions about improving listening proficiency by way of overcoming phonetic barriers.

\section{Phonetics AND Listening COMPREHENSION}

Rost (2002) explored the process of listening comprehension, from the standpoint of neurology, linguistics, psycholinguistics, pragmatics, and pedagogy, which reveals that listening comprehension is actually a very complicated process. The previous studies on listening comprehension provided some models to explain the process of listening comprehension.

\section{A. Bottom-up Model}

Shannon \& Weaver (1949) proposed the bottom-up processing model, according to which, listeners begin to comprehend the vocal message from the smallest auditory unit-segment or phoneme. From segments to words, phrases, clauses and then the whole sentence, sentences are formed into meaning, concepts and relationship. On the basis of this model, knowledge needed in listening comprehension is applied in a linear and hierarchical manner. In the process of communication, the speaker encodes the message, which is transmitted into the listener who decodes the message. If there is no message lost in transmission and the same codes are used by the speaker and listener, the communication between them is sure to succeed (Flowerdew \& Miller, 2005).

According bottom-up model, listening comprehension starts with understanding message of speech sounds. Without identifying and understanding speech sound, comprehension of the whole sentence or even the passage can hardly be achieved.

\section{B. Up-down Model}

That the contextual knowledge or knowledge about the world dominates the perception of vocal message is known as up-down processing model (Anderson, 2000). This model values the influence of previous knowledge of the listener instead of perception of individual segments on processing message.

Listeners will apply the structure of knowledge and discourse structure previously stored to understand speech. The

\footnotetext{
* This paper is part of results of Planning and Research Project of Social Science granted by Social Science Planning and Management Office of Shandong Province (15CWZJ21): Studies on EFL Learners' Aesthetic Ability in Phonetics and Phonetic Acquisition and it is also supported by Reform Project of Education and Teaching granted by Jining Medical University (14054) and Scientific Research Project granted by Jining Medical University (JY2013RW026).
} 
previously stored knowledge is known as schema. Once stored in form of schema, structure of some incident will help people to understand incidents taking place in the future and predict when the same or similar thing happens. This model can successful explain such a case in which the more familiar the listener gets with the topic of the passage, the easier he will understand.

According to this model, knowing the text structure and meaning macroscopically can compensates for comprehension at microscopic level, such as identifying segments, words and so on.

\section{Interactive Model}

Most studies have indicated that second language learners adopt both bottom-up processing and up-down processing model, which is known as interactive model. That is to say, listeners, on the one hand, comprehend sentence meaning by identifying segments and words, on the other hand, they also apply the previous knowledge to help their understanding.

However, learners of different levels trend to adopt different way of processing. Hildyard \& Olson (1982) found that high-proficiency learners are inclined to adopt both bottom-up and up-down processing while low-proficiency leaners are apt to focus on the details the listening materials. The author also found that many lower-proficiency leaners make a complaint about problems about identifying segments or cutting streams, which proves that effective up-down processing is based on bottom-up processing.

\section{Three-stage Model}

Cognitive psychology takes comprehension as processing of message (Neisser, 1967). Anderson (1995, 2000) believes that language comprehension can be divided into three stages, consisting of perception and processing, analysis and application. In the stage of perception and processing of oral language, the main task of a listener is to identify speech sounds, namely, to cut speech into segments and identify them. The second stage is also called syntactic analysis. Listeners cut speech into words and phrases according to syntactic structure and semantic clues. And meaningful mental representation is constructed based on linguistic structure, rules and semantic constraints. In the third stage, listeners apply their mental representation through combining mental representation of the textual meaning with proposition or schemata in long-term memory.

\section{E. Poelmans'Model}

Poelmans (2003) believes that the process of comprehending spoken language can be described as an inference process based on perceiving clues, rather than a process of simple match between sound and meaning. Listening comprehension is process consisting of four sub-processes: perception of sounds, classification of sounds, identification of words and comprehension.

First, perception of sounds helps listeners to make a distinction between human vocal sounds and background sound. Second, listeners classify the perceived input sounds according to phonetic categories of the language in question. Phones can be classified from different angles. For example, sounds can be classified into voiceless sounds and voiced sounds. Moreover, oral language has suprasegmental features, which are concerned with whole syllables or bigger units instead of a certain segment. Listeners cut successive speech into smaller units of language according to these suprasegmental features, such as pause, tone, stress and so on. Third, words that are retrieved from successive speech are matched with the meaning stored in long-term memory. Fourth, communicative purpose of the speaker is reconstructed by comprehending sentences combined by identified words according to their order.

Although there are several models about listening comprehension, it has been acknowledged that perception and identification of segments is the basic step to processing speech or vocal symbols. Comprehension of speech usually begins with perceiving or identifying speech, i.e. cutting streams into recognizable segments, syllables or words. Hence, identifying segments and cutting streams correctly is a most important and basic link in processing speech.

There are also some empirical studies proving that phonetic ability has relationship with listening comprehension. (Yao, 2009; Li, 2010; Fan, 2012)

If listeners has difficult in perceiving and identifying segments or successive speech, listening comprehension will be greatly hindered.

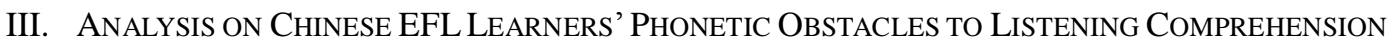

In this part, based on the author's experience of teaching Chinese EFL learners, obstacles from individual segments, sound changes in successive speech, stress, rhythm, intonation and English varieties will be explored.

\section{A. Obstacles from Individual Segments}

Due to the difference between Chinese and English, it is difficult for Chinese EFL learners to identify some English segments.

Firstly, some learners have great difficulty in identifying between short and long vowels, such as / । / and /i: /, and / $v$ / and /u: /. So, in listening, fit/f I t/ is heard as feet /fi:t/, and pool /pu:1/ as pull / pol / , to name but a few.

Secondly, some similar sounds like /e/ and / æ/, /a : / and / $/$, /s/, / $\int /$ and / $\theta /$, and /v/ and /w/ often lead Chinese EFL learners into great confusion when listening. Bed is often heard as bad, while staff as stuff and so on.

As we know, these phonemes mentioned above are contrastive in that change of one into the other one will bring 
about change of meaning of words. If the listener can't identify or perceive the segments correctly, he or she will get a different word or meaning far from the target word.

\section{B. Obstacles from Sound Change in Fluent Speech}

Apart from perceiving and identifying individual segments, listeners should also get familiar with various changes of the segments in fluent speech. Otherwise, they will feel like being faced with a strange string of sounds without any meaning or even perceived as a completely different word. Barriers from sound change in fluent speech mainly include the following categories.

1. Linking: Linking is a phonetic phenomenon commonly occurring in natural speech. According to Wang (2005: 120), when speakers of English are speaking, they arrange words into groups and join together the stressed and unstressed words within the group. They move smoothly from one word to the next without making any sudden stops. So when we listen to their speech, we hear the end of one word flow straight into the beginning of the next.

Look at the following examples:

3-1 I need $\cup^{1}$ it $\cup$ on.

3-2 John won $\cup$ an $\cup$ air ticket.

3-3 later $\cup$ on

3-4 my $\cup$ arm

These examples show that linking often occurs between a former word ending with a consonant or /r/ sound and a latter word ending with a vowel, which can be seen in sentence 3-1, 3-2 and 3-3. Besides, linking can also occurs when the preceding words ends with a vowel and the following word begins also with a vowel, as is shown in 3-4, and usually a slight $/ \mathrm{j} /$ or $/ \mathrm{w} /$ is added between two words.

In the process of listening, lots of learners, especially low-proficiency learners, often fail to perceive the linking between words, which results in confusion about the meaning of the string of sound. Examples in dictation will be cited here to illustrate the barriers from linking.

TABLE I.

MISTAKES RESULTING FROM LINKING OBSTACLES

\begin{tabular}{|l|l|}
\hline Target sentences for listening & Mistaken sentences in listening \\
\hline 1. We often go over to my $\cup$ uncle's. & We often go over to my young course. \\
\hline 2. You are not safe $\cup$ on the road. & You are not safe from the road. \\
\hline 3. My $\cup$ ears hurt. & My years hurt. \\
\hline 4. Tell $\cup$ us all about it. & Telas all about it. \\
\hline
\end{tabular}

In table I, the left column shows the target sentences for listening, while the right column shows the mistaken sentences in listening. This table shows the mistakes resulting from linking obstacles when Chinese EFL learners listen to sentences. Because the listener does not master linking in English speech, he cannot cut the stream of sound correctly into sounds encoded originally by the speaker, which lead into a distorted meaning.

2. Assimilation: assimilation is a process in which one sound is changed into another sound similar to its neighboring sound. In regressive assimilation, the former sound is influenced by the latter sound. For example, five past/faivpa : st/ is pronounced as / faifpa: st /. In progressive assimilation the latter sound is influenced by the former one. For example, cabs/ kæbs / is pronounced as /kæbz/. In reciprocal assimilation, two neighboring sounds influence each other and change into a new sound. For example, last year /la : st jiə/ is pronounced as / la : $\mathrm{s} \mathrm{t} \int \mathrm{\rho} / \mathrm{s}$. In this example, /t/ and /j/ influence each other and change into a completely different sound / $\mathrm{t} \int \mathrm{l}$.

If the listener can't perceive the change of the sound when assimilation occurs, mistakes will be made in listening. Mistakes resulting from not identifying assimilation are shown in the following table.

TABLE II.

MISTAKES RESULTING FROM ASSIMILATION OBSTACLES

\begin{tabular}{|l|l|}
\hline \multicolumn{2}{|c|}{ MISTAKES RESULTING FROM ASSIMILATION OBSTACLES } \\
\hline Target linguistic forms & Mistakes in listening \\
\hline 1. It doesn't fit you. & It doesn't fetch her. \\
\hline 2. love to & larf to \\
\hline
\end{tabular}

In table II, the left column shows the target linguistic forms while the right column shows mistakes made when Chinese EFL learners listen to them. Because of obstacles from assimilation, the listener can't perceive the correct forms of the target sentence or phrase.

3. Loss of plosion: when a word ends with a plosive sound, and the next word begins with another plosive or fricatives, affricates, nasals and laterals, the former plosive will lose plosion. For example:

what time/wot ${ }^{2}$ taim/,

sit down /sitdaun/,

good father /god fa : ðə/,

\footnotetext{
1 The symbol " $\cup$ " is used to indicate there is a linking when two neighboring words are quickly spoken out.

2 A line under the segment means that it loses plosion.
} 
big jeep /bıgdzi : p/

mad man / mæd mæn /

Besides, loss of plosion takes place within a word. For example, picture / pıkt $\int ə$ / and notebook/ nəotbok /.

Loss of plosion is just like losing a sound in a successive speech, which definitely brings about obstacles in identifying words and phrases. Here are some examples resulting from failing to identify loss of plosion.

TABLE III.

MISTAKES DUE TO OBSTACLES FROM LOSS OF PLOSION

\begin{tabular}{|l|l|}
\hline Target linguistic forms & Mistakes in listening \\
\hline 1. He asked twice. & He ask twice. \\
\hline 2. They came at last. & They camer last \\
\hline 3. lamppost & lampost \\
\hline
\end{tabular}

Table III shows mistakes due to obstacles from loss of plosion. Chinese EFL learners have difficulties in identifying the past tense of a word ending with -ed when it is followed by a word beginning with a plosive, like in example 1 in the table. The mistake occurred in example 2 is due to the fact that the listener fails to perceive the existence of sound / $t /$ in at because it losses plosion when it is followed by the next word starting with a lateral /l/, although the listener perceives the link between came and at. Mistakes resulting from failing to perceiving loss of plosion often take place within a word, like in example 3.

4. Weak forms: many function words in English have two pronunciations: a strong form (or stressed form) and a weak form (or reduced from, unstressed form). Weak forms are often adopted in fluent speech.

TABLE IV.

STRONG FROMS AND WEAK FORMS OF SOME FREQUENTLY USED WORDS

\begin{tabular}{|c|c|c|}
\hline Words & Strong form & Weak form \\
\hline $1 . \mathrm{a}$ & /el/ & / ə / \\
\hline 2.the & /ði:/ & /ðə/ \\
\hline 3.he & /hi:/ & $/ \mathrm{hl} /, / \mathrm{l} /$ \\
\hline 4.her & /hə:/ & / hə /, / ə:/, /ə/ \\
\hline 5.are & /a:/ & $/ 2 /$ \\
\hline 6.have & /hæv/ & /həv/, /əv/, /v/ \\
\hline 7.for & /fo : / & /f ə /, /fr/ \\
\hline 8.and & /ænd/ & /ənd/, /ən/, /nd/, /n/ \\
\hline 9. there & /ðеә/ & /ð ә / \\
\hline
\end{tabular}

Table IV shows strong forms and weak forms of some frequently used words. And there are other words with weak forms, which are not listed one by one. It is important to use the weak forms in English. Learners who are not familiar with the use of weak forms are likely to have difficulties in understanding native speakers. Some faults resulting from failing to identifying the weak forms are shown in the below table.

TABLE V.

MISTAKES DUE TO OBSTACLES FROM WEAK FORMS

\begin{tabular}{|l|l|}
\hline \multicolumn{2}{|c|}{ MISTAKES DUE TO OBSTACLES FROM WEAK FORMS } \\
\hline 1. What's her name? & Mistakes in listening \\
\hline 2. What did he do? & What's a name? \\
\hline 3. We had fish and chips. & What did do? \\
\hline
\end{tabular}

In table V, her in the first sentence adopts the weak form / / / and further / $/$ / is linked to the former / wbts /, changing into / wotsə /, which can explain why "what's her name?" is perceived as "What's a name?" Similarly, in example 2 in the above table, the listener doesn't perceive the weak form of he, resulting in loss of sound / । /. In listening the third sentence, the listener makes a mistake resulting from not perceiving the weak of and, taking "fish and" as "fishing".

All in all, in successive speech, some sounds are changed due to linking, assimilation, loss of plosion or adopting weak forms. Chinese EFL learners make some mistakes in listening because of failing to perceiving and identifying these sound changes.

\section{Obstacles from Stress}

In English, there are two kinds of stress, depending on the context in which stress is considered: word stress and sentence stress.

The location of stress can distinguish meaning. Word stress, sometimes, is the only standard for distinguishing two words. For example, import (stress on the first syllable) is different from import (stress on the second syllable). If the learners ignore the remembrance of stress of the words when learning a new word, they will not be sensitive to the movement of stress. In addition, learners always meet obstacles from the stress movement when hearing a derivational form of a word. For example, it's much easier for Chinese EFL learners to perceive sincere than sincerity.

Sentence stress refers to the relative force given to the components of a sentence. Whichever part of the sentence is stressed is mainly determined by the speaker's intention. Meaning of a sentence is changed with changes of sentence stress. For example: 
3-5 I went to the bar.

As for sentence 3-5, if stress is on the word I, it means "I", not other persons, went to the bar. If the stress is on the word bar, instead of other words, the sentence means that I went to the bar instead of other places. If the listener doesn't focus on the stressed word, he will not get the real meaning of the speaker.

To sum up, perceiving stress of a word and a sentence is very important in listening, especially in listening to a conversation and a passage. Without identifying stress, the listener will maybe fail to understand the intention of the speaker.

\section{Obstacles from Rhythm}

Every language has its own rhythmic patterns. Chinese rhythm represents itself in the collocation among its various tones, while English rhythm is realized by alternative appearance of the stressed and unstressed syllables. In addition, Chinese is syllable-timed, while English is stress-timed. That's to say, it will take more time to say a Chinese sentence with more words than that with less words. In English, it will take the same time to say a sentence with the same number of syllables, without considering the number of words in the sentence. For example:

3-6 这个男孩很想扩大他的词汇量。

3-7 每天进步很大。

3-8 The '3 boy is 'interested in en'larging his vo'cabulary.

3-9 'Great 'progress in 'made 'daily.

There are two Chinese sentences, sentence 3-6 and sentence 3-7. There are thirteen words in sentence 3-6, and six words in sentence 3-7. Obviously, it will take more time for a Chinese to say sentence 3-6 than sentence 3-7. Sentences 3-8 and 3-9 are the corresponding English sentence for 3-6 and 3-7. Although these two English sentences have different number of words, they both have four stressed syllables. Hence, it will take the same time to say these two English sentences.

Chinese EFL learners are not familiar the English stress-timed rhythm. Some of the learners think that the speaker speaks sometimes faster and sometimes slower, and it's difficult for them to understand the quicker part of the sentence.

\section{E. Obstacles from Intonation}

When pitch, stress and sound length are tied to the sentence rather than the word in isolation, they are collectively known as intonation. English has two basic intonation patterns: the falling tone and the rising tone. When they go together, they can make a falling-rising tone. Generally speaking, the falling tone indicates that the speaker is stating a fact, the rising tone often makes a question of what is said, and the falling-rising tone often indicates that there is an implied message. Intonation plays an important role in conveying meaning in English. For example:

3-10 I can't eat anything.

The above sentence 3-10 means that I can eat nothing if said in a falling tone, while it implies that there are particular things that I can't eat if said in a fall-rise tone.

Chinese is not an intonation language, but a tone language. It has four tones: the first tone is level, the second rise, the third fall-rise and fourth fall. If a word is spoken in different tones, it has totally different meaning.

For some Chinese EFL learners, it is difficult for them to perceive the different meaning due to change of intonation. And sometimes they don't catch the speaker's meaning accurately or even misunderstand the speaker.

\section{F. Obstacles from English Varieties}

English has become an international language as time goes by and there are a couple of varieties, such as British English, American English, Canadian English, Australian English and so on. In China, EFL learners mainly have access to British English and American English. At the beginning, they learn British English pronunciation, while after a while or entering colleges, they mainly listen to American English. Therefore, most listeners get confused about identifying some words owing to their different pronunciation. For example, words easily bringing about difficulties include class, hard, path, schedule, bottle, city, etc. Even though they knew the different pronunciation of the word in British English and American English as some listeners reported, it would take them much time to identify which word it is exactly, which then affects perceiving the following information.

Based on what is discussed above, we are confirmed that Chinese EFL learners have encountered many phonetic barriers on listening due to the difference between Chinese and English pronunciation features.

\section{Suggestions to Improving Listening COMPREHENSION By OVERCOMing PhONETiC ObSTACLES}

Identifying and perceiving sound of speech is vital to listening comprehension. Overcoming phonetic obstacles is obviously an effective way to improving listening comprehension.

In China, according to the undergraduate program for English majors, the course of English pronunciation is only provided in the first semester of the first year in almost all the colleges and universities. What's worse, there is no independent phonetic course for non-English majors. Pronunciation is rarely involved in later learning.

\footnotetext{
3 The symbol "'" stands for stress on the syllable.
} 
On the one hand, in the course of English listening, most teachers place stress on explanation of meaning and usage of new words, introducing background information related with the topic, and explanation of long sentences that cause difficulties in reading. They seldom lead students to pay attention to difficulties causing by phonetics. On other hand, students pay more attention to the meaning and spelling of a new word instead of its pronunciation. The result is that they know the word when they see it, while sometimes they can't even perceive it when they listen to it, not to speak of identifying similar sounds, sound change in fluent speech, and other aspects. Based on this situation, suggestions are given below.

\section{A. Increasing Phonetic Teaching in Listening}

1. Increasing phonetic teaching for Chinese non-English majors. In China, non-English majors are neither offered English phonetic course, nor taught any knowledge of English phonetics systematically in class, because it is believed that they have taught phonetic knowledge in middle school. In fact, they don't receive any formal teaching about English phonetics, partly because phonetic knowledge is not the most important part in college entrance examination. College English teachers should spend longer time in teaching phonetics in class or by way of Micro-Course Online Video.

2. Increasing phonetic teaching for English majors. In China, English majors are offered English phonetics course in the first semester. In fact, it's impossible for students to completely master English pronunciation and intonation, especially sound change in fluent speech in such a short time. So, it's necessary for teachers not to ignore teaching of pronunciation especially in the course of English listening. Whenever students make mistakes due to obstacles from English phonetics, teachers should point it out immediately and appeal students' attention to analyze the mistakes from the perspective of phonetics.

Similar sound distinction, sound change in speech, stress, rhythm, intonation and different pronunciation between British English and American English should be emphasized.

\section{B. Memorizing the Sound Form of a Word}

Chinese EFL learners are always playing stress on reading and writing ability, rather than listening and speaking ability. It is common to find that students only memorize the spelling form and meaning when they meet a new word. Given the neglect of memorizing the sound form of a word, students are required to make great efforts to memorize their sound forms. Once the relationship between the sound form and it meaning is established, it will be easier and quicker to understand meaning.

1. Memorizing words through listening. Obstacles from phonetics are basically due to lack of listening. In China, EFL learners spend most of the time in intensively and extensively reading passages. In contrast, they seldom spend time in practicing listening. It is acknowledged that frequency plays an important role in language acquisition (Ellis, 2002; Bybee, 2008; Ellis, 2012). Learners can acquire a word by listening more to it. The more learners listen to words, and sentences, the quicker they retrieve them from the brain.

2. Memorizing words through reading. Lu (2001) pointed out, effective reading is basic to listening comprehension and it can directly promote improvement of listening ability. Effective reading means reading with standard pronunciation, natural sound change, good rhythm, and proper intonation.

Memorizing the sound form of a word should include not only the strong form, but also weak form, its stress, and even intonation of the word. Once familiar with the sound form of a word, students will speed their decoding of the word and connecting the sound to its meaning.

\section{Dictation}

Dictation is a kind of intensive listening. Every words should be written down while learners listening. So, it's an effective way to test accuracy of listening comprehension. With more dictation, listeners can find their weaknesses in identifying similar sounds, sound changes, stress, rhythm, intonation and British English or American English.

Teachers can design some tasks of dictation. From dictating words and phrases to sentences and passages, students can sum up experience from dictation by overcoming obstacle from phonetics.

\section{CONCLUSION}

Listening comprehension is a complicated process, in which whether identifying segments, especially similar segments and perceiving sound change in speech, movement of stress, rhythm, intonation, and varieties are vital to listening comprehension. Getting knowledge of phonetic obstacles in listening can help to improve Chinese EFL learners' listening comprehension. Increasing phonetic teaching in listening, memorizing the sound form of the word and designing dictation tasks are suggested to improve Chinese EF Learners' listening comprehension from the perspective of overcoming phonetic obstacles.

\section{REFERENCES}

[1] Anderson, J. R. (1995). Cognitive Psychology and Its Implications (4 ${ }^{\text {th }}$ ed.). New York: Freeman.

[2] Anderson, J. R. (2000). Cognitive Psychology and Its Implications (5 $5^{\text {th }}$ ed.). New York: Worth Publishing. 
[3] Bybee, J. L. (2008). Usage-based grammar and second language acquisition. In P. Robinson \& N. Ellis (eds.), Handbook of Cognitive Linguistics and Second Language Acquisition. New York \& London: Routledge, 2016-236

[4] Ellis, N. (2002). Frequency effects in language acquisition. Studies in Second Language Acquisition 24.2, 143-188.

[5] Ellis, N. (2012). Frequency-based accounts of SLA. In S. Gass \& A. Mackey (eds.), The Routledge Handbook of Second Language Acquisition. London \& New York: Routledge, 193-210.

[6] Fan, Shuling. (2012). Correlation Study on Phonetic Level and Listening Comprehension Competence for Students of Non-English Majors. Journal of Taiyuan Normal University (Social Science Edition) 11.6, 95-98.

[7] Flowerdew, J. \& Miller, L. (2005). Second Language Listening: Theory and Practice. New York: Cambridge University Press.

[8] Hildyard, A. \& Olson, D. R. (1982). On the comprehension and memory of oral vs. written discourse. In D Tannen (Eds.), Spoken and Written Language: Exploring Orality and Literacy. Norwood, NJ: Ablex, 19-24.

[9] Li, Suwei. (2010). Phonological Competence and Listening Comprehension: A Correlation Analysis. Journal of Zhangjiang Normal College 31.5, 142-146.

[10] Lu, Minxia. (2001). English reading and improvement of listening and speaking ability. Journal of Yangzhou University (research of Higher Education) 3, 50-53.

[11] Neisser, U. (1967). Cognitive Psychology. New York: Appleton-Century-Crofts.

[12] Poelmans, P. (2003). Developing second-language listening comprehension: Effects of training lower-order skills versus higher-order strategy. Unpublished Ph.D. dissertation. Amsterdam: University of Amsterdam.

[13] Rost, M. (2002). Teaching and Researching Listening. London: Longman.

[14] Shannon, C. E. \& Weaver, W. (1949). A Mathematical Model of Communication. Urbana, IL: University of Illinois Press.

[15] Wang, Guizhen. (2005). English Pronunciation \& Intonation for Communication ( ${ }^{\text {nd }}$ ed.). Beijing: China Higher Education Press.

[16] Yao, Min. (2009). An Experimental Study of the Relationships between English Phonetic Ability and Listening Ability. Journal of Shanxi Radio \& TV University 71.4, 72-73.

Fanghui Hu, born in Jining, Shangdong Province in 1981. She received her Master Degree from Hunan University in 2007.

She is currently a lecturer in School of Foreign Languages, Jining Medical University, Rizhao, China. She has been teaching in Jining Medical University for ten years; courses taught include English listening, Introduction to Linguistics, English writing, and Stylistics. Her research interests include second language acquisition and language testing. 